\title{
Dış Kulak Yolunda Yabancı Cisim Olan Vakaların Değerlendirilmesi
}

\section{Evaluation of Patients with External Auditory Canal Foreign Bodies \\ Buğra Subașı ${ }^{1}$}

\begin{abstract}
1 Kütahya Sağlık Bilimleri Üniversitesi Tıp Fakültesi Evliya Çelebi Eğitim ve Araştırma Hastanesi Kulak Burun Boğaz Kliniği, Kütahya, Türkiye
\end{abstract}

Öz.

Amaç: Hem çocuklarda hem de erişkinlerde görülen dış kulak yolu yabancı cisimleri sık görülen kulak burun boğaz (KBB) acillerindendir. Yabancı cisme bağlı ve yabancı cismin çıkarılmaya çalışılması sırasında ciddi komplikasyonlar görülebilir. Dış kulak yolunda yabancı cisim olan olgularda yabancı cisim tipleri, komplikasyonları, tedavi yaklaşımları incelendi.

Materyal ve metod: Kasım 2016 ve Ağustos 2019 yılları arasında Sakarya Hendek Devlet Hastanesinde kulakta yabancı cisim nedenli tanı konulan 186 hasta retrospektif olarak incelendi. Yabancı cismin tipi, hastanın yaşı, cinsiyeti, hasta şikayetleri, yabancı cismin hangi tarafta sık görüldüğü, komplikasyonlar, tedavi yöntemleri kaydedildi.

Bulgular: 186 kişinin (116 erkek, 70 kadın; ortalama yaş: 36,7 yıl; dağılım: 9ay- 87 yıl) dış kulak yolunda yabancı cisim tespit edildi. 91 olguda (\%48.9) sağ kulakta, 87 olguda (\%46.8) sol kulakta, 8 olguda $(\% 4,3)$ her iki kulakta yabacı cisim izlendi. $6(\% 3,2)$ olguda tek kulakta birden fazla yabancı cisim izlendi. Hastaların 54 'ü $(\% 29) 16$ yaş altı çocuk, 132'si (\%71) erişkindi. Çocuklarda en sık boncuk (\%25,9), erişkinlerde en sık pamuk (\%25) izlendi. 179 hastadan poliklinik şartlarında anestezi kullanmadan yabancı cisim çıkartıııken, $7(\% 3,8)$ hastada genel anesteziyle yabancı cisim çıkarıldı.

Sonuç: Dış kulak yolu yabancı cisimleri komplikasyonlardan kaçınmak için uygun aletler kullanarak tecrübeli KBB hekimlerince otoskop ya da mikroskop yardımı ile iyi görüş sağlanarak dikkatlice çıkartılmalıdılar. Dış kulak yolunda yabancı cisim şikayetiyle gelen hastaların her iki kulağı dikkatlice muayene edilmeli yabancı cisim çıkarıldıktan sonra da olası başka bir yabancı cisim ya da komplikasyon varlığı açısından tekrar dış kulak yolu ve timpanik membran değerlendirilmelidir. Dış kulak yolu yabancı cisimleri hakkında halk bilgilendirilmelidir.

Anahtar Kelimeler: Yabancı cisim, Dış kulak yolu

Abstract

Background: External auditory canal foreign bodies, which are seen both in children and adults, are common otolaryngology emergencies. Serious complications may occur when trying to remove the foreign body and because of foreign body. To investigate the types of foreign bodies, complication rates, treatment protocols of patients with external auditory canal foreign bodies.

Materials and Methods: 186 patients who were diagnosed with foreign bodies in the external auditory canal were analyzed retrospectively between November 2016 and August 2019 in Sakarya Hendek State Hospital. Types of foreign bodies, age, gender, clinical symptoms, side of presentation, complications, treatment protocols were recorded.

Results: We detected 186 patients (116 males,70 females; mean age:36.7 years; range 9 month to 87 years) with external auditory canal foreign bodies. Foreign bodies were detected in right ear in 91 patients (\%48.9), and in left ear in 87 patients (\%46.8). 8 patients (\%4.3) had bilateral foreign bodies and 6 patients (\%3.2) had at least two foreign bodies in the same external auditory canal. 54 (\%29) patients were children under 16 years of age, 132 (\%71) were adults. Beads (\%25.9) were the most common foreign bodies in children, cotton (\%25) were the most common in adults. Foreign bodies were removed without use of any anesthetic agents in 179 patients but in $7(\% 3,8)$ patients they were removed under general anesthesia.

Conclusion: Foreign bodies should be removed carefully under good vision using an otoscope or under the microscope by experienced otorhinolaryngologists to prevent complications. Both ears of the patients coming with the complaint of foreign body in external auditory canal should be examined carefully and after the foreign body is removed, the external auditory canal and the tympanic membrane should be evaluated again for the presence of another foreign body or any complication. The public should be informed about external auditory canal foreign bodies.

Key words: Foreign body, External auditory canal

\section{Sorumlu Yazar I \\ Corresponding Author}

Buğra Subaşı

Kütahya Sağılık Bilimleri Üniversitesi Tıp Fakültesi

Evliya Çelebi Eğitim ve Araşıırma Hastanesi

Kulak Burun Boğaz Kliniği,

Kütahya, Türkiye

Tel: 05056374408

Fax: 0 (274) 2652285

Email: drbugrasubasi@hotmail.com

Geliş tarihi / Received:

08.01.2020

Kabul tarihi / Accepted:

11.06.2020

DOI: 10.35440/hutfd.672395 


\section{Giriş}

Yabancı cisimler KBB acillerinin \% 11'ini oluşturmaktadır. KBB konsültasyonlarının önemli sebeplerinden biri olan yabancı cisimler en sık kulakta izlenmekle beraber burun boşluğu ve orofarenkste de izlenebilmektedirler (1). Çocuklar buldukları nesneleri ağız, burun ve kulaklarına sokma eğilimindedirler bu nedenle yabancı cisimler çocuklarda erişkinlerden daha sık izlenmektedir (2). Dış kulak yolu yabancı cisimleri erişkinlerde özellikle kulağı temizlemek için kullandıkları cisimlerin kulak yolunda kalması, çocuklarda ise merak nedenli yabancı cisimleri kulaklarına sokmaları nedeniyle olmaktadır. Hastalar kulakta ağrı, tıkanıklık, çınlama, kanama, işitme kaybı gibi sebeplerle acil servislere ya da polikliniklere başvurdukları gibi bu cisimler rutin muayene sırasında da rastlantısal olarak saptanabilmektedirler $(3,4)$.

\section{Materyal ve Metod}

Kasım 2016 ve Ağustos 2019 yılları arasında Sakarya Hendek Devlet Hastanesi KBB kliniğinde dış kulak yolunda yabancı cisim tespit edilen 186 hastanın verileri retrospektif olarak incelendi. Hastaların yaş, cinsiyet, hasta şikayetleri, yabancı cismin tipi, hangi tarafta sık görüldüğü, komplikasyonlar, tanı tedavi yöntemleri kaydedildi. Tüm hastaların her iki kulağı da otoskop ile muayene edildi. Bazı hastalarda ek olarak mikroskobik ve teleskopik incelemeler yapıldı. Yabancı cisim çıkarıldıktan sonra olası komplikasyonlar açısından tekrar dış kulak yolu ve timpanik mebranlar dikkatlice değerlendirildi. Kronik kulak hastalığı olanlar, konjenital kulak hastalığı olanlar, kulak cerrahisi geçirenler çalışma dışı bırakıldı. Şikayet olmaksızın rutin muayene sırasında rastlantısal olarak tespit edilen yabancı cisimler çalışmaya dahil edildi. Kulağına yabancı cisim girdiğinden şüphelenip muayene olan ancak otoskopik muayenesinde yabancı cisim izlenmeyen hastalar çalışma dışı bırakıldı. Yabancı cisimler otoskop ya da mikroskop ile görüş sağlanarak alligatör forceps, buşon küreti, irrigasyon, aspiratör ile çıkarıldı. Çalışma Kütahya Sağlık Bilimleri Üniversitesi Girişimsel Olmayan Klinik Araştırmalar Etik Kurulu tarafından onaylandı (karar no:2020/01-16, tarih:02.01.2020).

\section{Bulgular}

Dış kulak yolu yabancı cismi tespit edilen 186 hastanın en küçüğü 9 aylık en büyüğü 87 yaşında ortalama yaş 36.7 yıl idi. Hastaların 116' sı (\%62.4) erkek, 70'i (\%37.6) bayandı. Yabancı cisim 91 olguda (\%48.9) sağ kulakta, 87 olguda (\%46.8) sol kulakta, 8 olguda (\%4.3) her iki kulakta izlendi. 6 olguda (\%3.2) tek kulakta birden fazla yabancı cisim izlendi. Çocuklarda en sık boncuk $(\% 25,9)$, erişkinlerde en sık pamuk (\%25) tespit edildi. Hastalar kulakta tıkanıklık, ağrı, akıntı, uğultu, işitme azlığı, kaşıntı gibi şikayetlerle başvursalar da hastaların çoğunda yabancı cisim rastlantısal olarak tespit edildi. Bazı çocuk hastalarda şikayet ol- maksızın ailelerin dış kulak yolunda yabancı cisim görmeleriyle yabancı cisimler tespit edilmiştir. Erişkin hastalarda en sık şikayet kulakta tıkanıklık hissiydi.

Tablo 1. Yaş gruplarına göre çıkarılan yabancı cisimlere ilişkin dağılımlar

\begin{tabular}{|c|c|c|}
\hline Yabancı cisim tipleri & $\begin{array}{c}0-15 \text { yaş } \\
\text { hasta sayısı }\end{array}$ & $\begin{array}{c}16-90 \text { yaş } \\
\text { hasta sayısı }\end{array}$ \\
\hline Boncuk & 13 & \\
\hline Boncuk + Tohum tek taraflı & 1 & \\
\hline Böcek & 5 & 15 \\
\hline Cam parçası & 1 & \\
\hline Çekirdek & 1 & \\
\hline İnşaat köpüğü & & 1 \\
\hline İşitme cihazı parçası & 1 & 2 \\
\hline Kağıt & 1 & \\
\hline Kağıt+Küpe tek taraflı & 1 & \\
\hline Kalem ucu & 3 & 1 \\
\hline Karpuz çekirdeği & & 1 \\
\hline Kibrit çöpü & 1 & 1 \\
\hline Kulak çöpü pamuğu & 1 & 15 \\
\hline Kulak damlası kapağı & & 1 \\
\hline Kulak tıkacı & & 2 \\
\hline Kulaklık ucu & & 1 \\
\hline Kum tanesi & 3 & 11 \\
\hline Kum tanesi İki taraflı & 3 & 3 \\
\hline Kum+Saç İki taraflı & & 1 \\
\hline Kuru dal parçası & & 3 \\
\hline $\begin{array}{l}\text { Pamuk+Kalemucu+Dal parçası tek } \\
\text { taraflı }\end{array}$ & 1 & \\
\hline Küpe & 2 & \\
\hline Lego & 1 & \\
\hline Naylon & 2 & \\
\hline Ot & & 24 \\
\hline Pamuk & 1 & 30 \\
\hline Pamuk iki taraflı & & 1 \\
\hline Pamuk+Pamuk tek taraflı & & 1 \\
\hline Pamuk+Peçete tek taraflı & & 1 \\
\hline Pamuk+Sarımsak tek taraflı & 1 & \\
\hline Peçete & 2 & 3 \\
\hline Pil & 1 & \\
\hline Saç teli & 2 & 7 \\
\hline Sarımsak & & 1 \\
\hline Taş & 5 & 2 \\
\hline Tesbih tanesi & & 1 \\
\hline Tohum & 1 & 3 \\
\hline Toplam & 54 & 132 \\
\hline Genel Toplam & 186 & \\
\hline
\end{tabular}

$7(\% 3,8)$ hastada yabancı cisimler ameliyathane şartlarında genel anestezi ile mikroskop kullanılarak çıkarılmıştır. 179 (\%96.2) vakada yabancı cisimler poliklinik şartlarında otoskop ile görüş sağlanarak alligatör forceps, buşon küreti, irrigasyon ya da aspiratör yardımıyla çıkarıımıştır. Yabancı cisme bağlı 4 (\%2.2) hastada otitis eksterna, 1 $(\% 0.5)$ hastada yabancı cisim başka bir merkezde çıkarımaya çalışıldığı için dış kulak yolunda laserasyon mevcuttu. Postoperatif hiç bir hastada komplikasyon izlenmedi. Tüm hastaların timpanik membranları intakttı. 


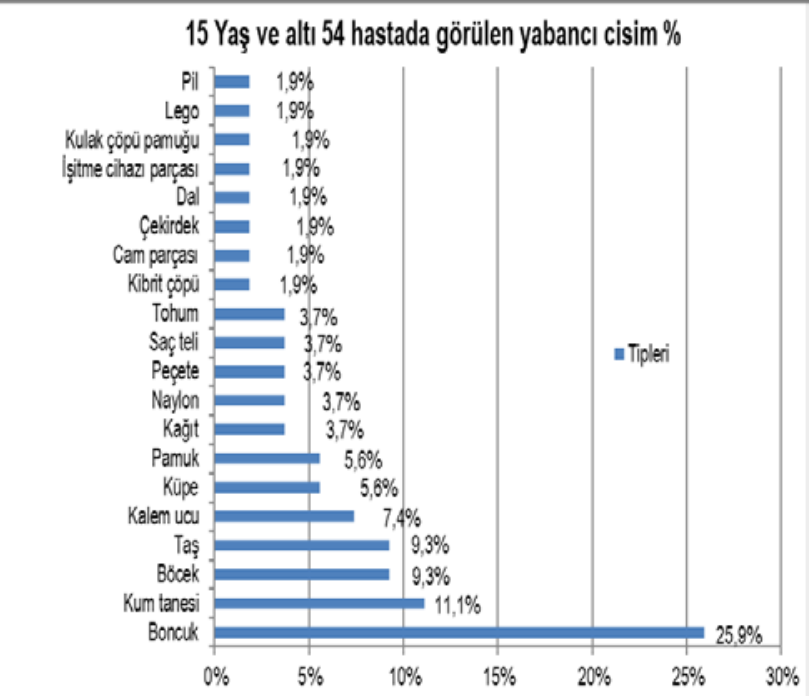

Şekil 1. 15 yaş ve altı dış kulak yoluna kaçan cisimlerin dağı̆ımı

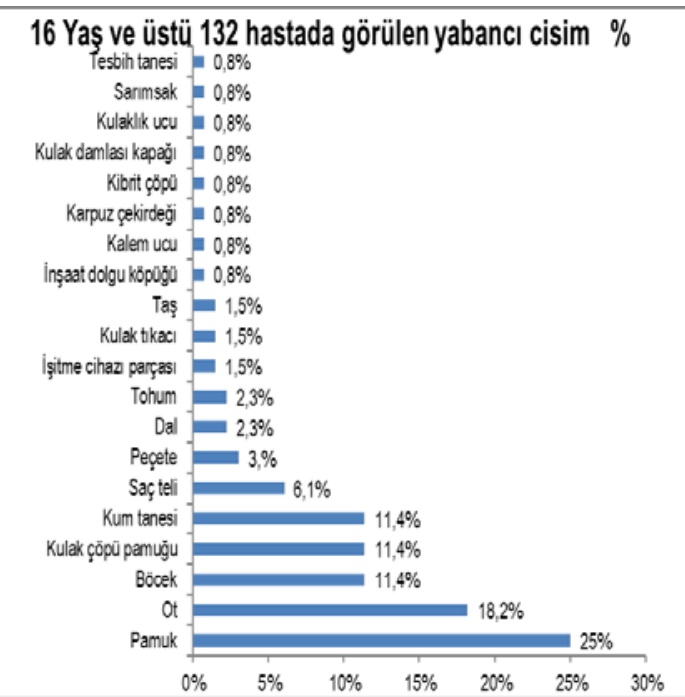

Şekil 2. 16 yaş ve üstü dış kulak yoluna kaçan cisimlerin dağılımı

\section{Tartışma}

Dış kulak yolu yabancı cisimleri organik-inorganik, canlıcansız, higroskopik olan- higroskopik olmayan, madeni olan-madeni olmayan, düzenli-düzensiz, yumuşak-sert diye sınıflandırılabilirler (5). Yabancı cismin çıkarııma şekli yabancı cisimlerin bu fiziksel özelliklerine, yabancı cismin dış kulak yolu ya da orta kulak yerleşimine, hastanın uyumuna bağlıdır. Yabancı cisim tipleri erişkinler ve çocuklarda farklılıklar göstermektedir. (3)

IIlhan ve ark. (6) yaptıkları çalışmada erişkinlerde en sık böcekler, kulak çöpü pamuğu, çocuklarda ise tohum, boncuk, plastik oyuncak parçaları saptamışlardır. Gül ve ark. (7) çocuklarda en sık boncuk ve böcek, erişkin hastalarda en sık böcek tespit etmişlerdir. Schulze ve ark. (5) yaptığı çalışmada çocuklarda boncuk, mısır taneleri ve kağıt parçaları en sık görülen yabancı cisimlerdi. Yegin ve ark. (8) 0-6 yaş grubunda en sık boncuk ve plastik oyuncak parçaları, 7-15 yaş grubunda kesici delici aletler, boncuk, kulak çöpü pamuğu, 16 yaş üstü grupta ise en sık kulak çöpü pamuğu tespit etmiş̧lerdir. Shingh ve ark. (9) dış kulak yolunda en sık tohum, tahıl, bitki, plastik, oyuncak parçaları, pamuk, kağıt parçalarına rastlamışlardır. Al-Juboori. (10) yaptığı çalışmada dış kulak yolunda en fazla boncuk ve kulak çöpü tespit etmiş̧ir. Bizim çalışmamızda çocuklarda en sık boncuk, erişkin hastalarda en sık pamuk tespit edilmiştir. Yegin ve ark. (8) yaptığı çalışmada yabancı cisimler en sık sağ kulakta izlenmiş, 11 hastada her iki kulakta saptanmıştır. Illhan ve ark. (6) yabancı cisimlere her iki tarafta birbirine yakın oranda rastlamışlardır. Thompson ve ark. (3) her iki kulak arasında anlamlı fark olmadığını bildirmişlerdir. Olajide ve ark. (4) yaptıkları çalışmada sağ kulakta yabancı cisimlerin daha sık görüldüğünü bildirmişlerdir. Bizim çalışmamızda yabancı cisimler 91 (\%48.9) hastada sağ kulakta, 87 hastada (\%46.8) sol kulakta tespit edilmiştir. Yabancı cisimler \%2-14 oranında iki taraflı olabilir. Karşı kulaktaki yabancı cisim asemptomatik olabilir. Muhakkak diğer kulak da muayene edilmelidir (11). Bizim çalışmamızda 8 olguda (\%4.3) her iki kulakta, 6 (\%3.2) olguda tek kulakta birden fazla yabancı cisim izlendi. Da Silva ve ark. (1) cinsiyetler arasında yabancı cisim görülme sıklığında fark olmadığını belirtse de literatürde erkeklerin kadınlara oranla kulaklarına daha fazla yabancı cisim soktuğuna dair yayınlar mevcuttur $(4,12,14)$. Bizim çalışmamızda erkek sayısı fazla olup hastaların 116'sı (\%62.4) erkek, 70'i (\%37.6) bayandı.

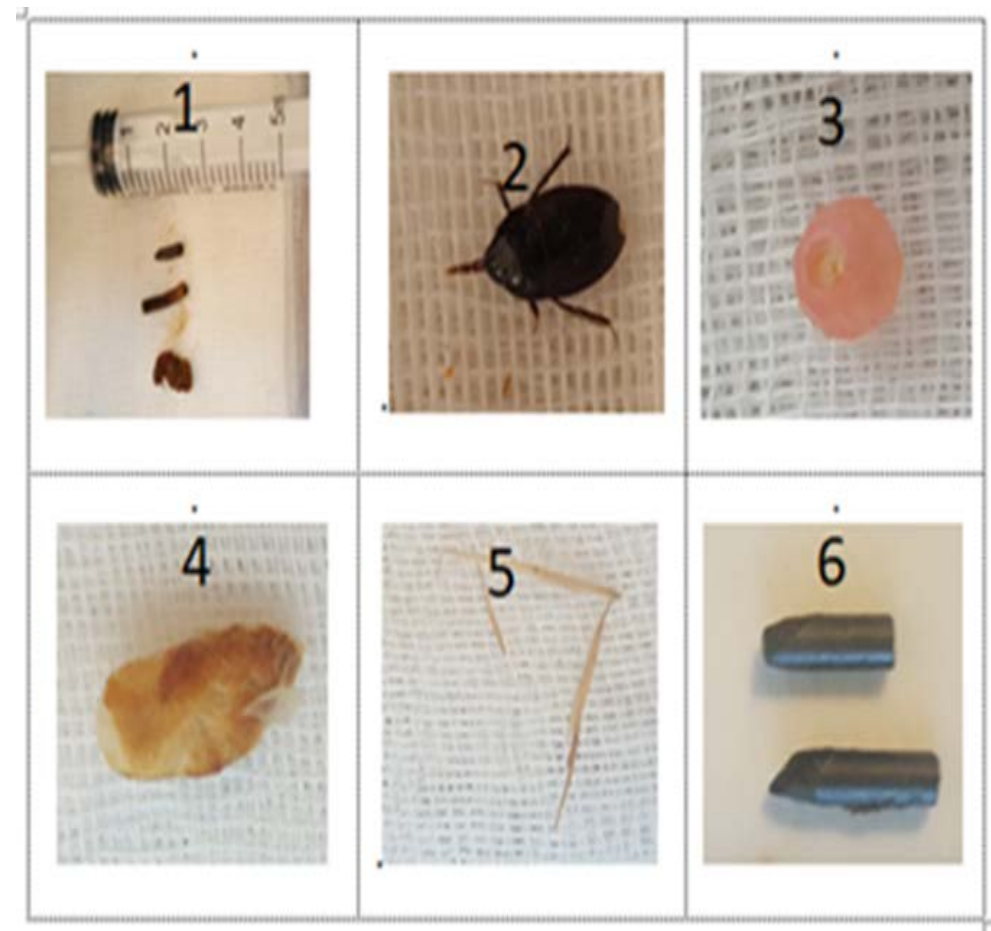

Şekil 3. Dış kulak yolundan çıkarılan bazı yabancı cisimler 1)Pamuk, kurşun kalem ucu, kuru dal parçası, 2)Böcek, 3)Boncuk, 4) Pamuk, 5)Ot, 6.) Kurşun kalem ucu 
Literatürde çocuklarda yabancı cismin daha fazla görüldüğüne dair çok sayı da yayın bulunmaktadır $(10,12,14)$. Bizim çalışmamızda erişkin hastalarda yabancı cisim daha çok izlendi. 186 hastanın 132'si erişkin 54'ü çocuktu.

Tedavide amaç komplikasyona yol açmadan poliklinikte ya da ameliyathanede uygun aletler kullanılarak cismin dış kulak yolundan çıkarımasıdır. Hastanın uyum durumu, yabancı cismin yerleşim yeri, şekli ve tipi göz önüne alınarak ameliyathane ortamı, anestezi gerekip gerekmeyeceğine karar verilir. Aligatör forseps, aspiratör, küret, açılı hook, hartman forseps kullanarak ve irrigasyon yaparak yabancı cisimler çıkarılabilir. Kulak zarı perforasyonu varsa, disk pilleri ve sebze, fasulye gibi higroskopik cisimler mevcudiyetinde irrigasyon yapılmamalıdır (12). Yegin ve ark. (8) 15 olguda (\%6.4) genel anesteziyle yabancı cisimleri çıkarmışlardır. Gül ve ark. (7) 158 hastanın 4'ünde sedasyon anestezisi kullanmışlardır. Bu çalışmada $7(\% 3,8)$ hastada yabancı cisimler ameliyathane şartlarında genel anestezi ile mikroskop kullanılarak çıkarılmıştır. Yedi hastanın hepsi çocuktu. ìki tanesinde büyük, sivri kenarlı taş, 1 tanesinde şişmiş dış kulak yolunu tıkamış tohum tanesi, 2 tanesinde boncuk, 1 tanesinde zar üstü ölmüş böcek, bir diğerinde aynı dış kulak yolunda tohum ve boncuk mevcuttu. Hastalar hem aijteydi hem de cisimlerin büyüklük ve şekilleri göz önüne alındığında komplikasyona yol açmamak için anestezi eşliğinde çıkarılmalarına karar verildi. Dış kulak yolu yabancı cisimlerine bağlı ve yabancı cisim çıkarılırken çeşitli komplikasyonlar olabilir. Ansley ve Cunningham. (13) yaptıkları çalışmada uygun alet eksikliği, uyumsuz çocuk hastayı sakinleştirecek personel yokluğu, ilk müdahalede yabancı cismin çıkmaması, dış kulak yolu ve ya kulak zarı yaralanması, dış kulak yoluna sıkışmış veya zar üstünde yabancı cisim olması, keskin kenarlı cisim, böcek, macun, pil mevcudiyeti gibi özel durumlarda hastaların KBB hekimine yönlendirilmesi gerektiğini savunmuşlardır. İlk müdehale yabancı cismi çıkarmak önemlidir çünkü ilk müdehalede yabancı cisim çıkmazsa başarı oranı düşer komplikasyon oranları artar. Kanal abrazyonu, laserasyon, kanama, timpanik membran perforasyonu, kemikçik zincir hasarı ve işitme kaybı gibi komplikasyonlar görülebilir $(5,10,14)$. Olajide ve ark. (4) yaptıkları çalışmada KBB hekimleri tarafından çıkarılan yabancı cisimlerde komplikasyon oranının daha düşük olduğunu tespit etmişler Singh ve ark. (9) komplikasyon oranının düşük olması, genel anestezi intiyacının azalması ve tedavi maliyetinin düşmesinden ötürü tüm dış kulak yolu yabancı cisimlerinin KBB hekimleri tarafından görülmesi gerektiğini ifade etmişlerdir. IIhan ve ark.(6) yaptıkları çalışmada yabancı cisim çıkarılması sırasında en sık komplikasyon olarak dış kulak yolu ve timpanik membran üzerinde yaralanma $\% 15.38, \% 3.41$ otitis eksterna, \% 2,56 ile timpanik membran perforasyonu tespit etmişlerdir. Yegin ve ark. (8) yaptıkları çalışmada komplikasyon olarak en sık \%12 oranında dış kulak yolu ve timpanik membran abrazyonu ve \%8.6 oranında timpanik membran perforasyonu saptamışlardır. Gül ve ark. (7) dış kulak yolu ve timpanik mebranda laserasyon, eksternal otit ve timpanik membran perforasyonu tespit etmişlerdir. Yabancı cisme bağı ınfeksiyon \%2-7 oranında izlenmekte olup neredeyse tamamı otitis ekterna şeklinde görülmektedir. Dış kulak yolu yabancı cisimleri nadiren otitis media, mastoidit, menenjit, beyin apsesi gibi enfeksiyonlara neden olabilir (15). Bizim çalışmamızda postoperatif herhangi bir komplikasyona rastlanmadı. Sadece 4 (\%2.2) vakada yabancı cisim kaynaklı otitis eksterna ve bir hastada dış merkezde çıkarılmaya çalışılıı̆ı için dış kulak yolunda laserasyon mevcuttu.

Dış kulak yolu yabancı cisimleri sık görülen KBB acillerinden olup komplikasyona yol açmaması için deneyimli KBB hekimleri tarafindan uygun aletler kullanılarak otoskop ya da mikroskop yardımı ile çıkarımalıdırlar. Hastaların her iki kulağı dikkatlice muayene edilmeli yabancı cisim çıkarıldıktan sonra da olası başka bir yabancı cisim ya da komplikasyon varlığı açısından tekrar dış kulak yolu ve timpanik membran değerlendirilmelidir. Erişkin hastalar pamuk ve kulak çöpü pamuğu kullanmamaları konusunda ayrıca çocuklara alınacak kıyafet ve oyuncakların boncuk, küçük parçacıklar içermemesi konusunda bilgilendirilmelidirler. Kırsal kesimde yaşayanların kulaklarına ot ve böcek kaçabileceğini bilmeleri ve önlem almaları gerekmektedir. Deniz tatili yapan kişilerin kulaklarını kumdan korumaları ayrıca saç kesimi sırasında dışkulak yoluna küçük saç parçacıkIarının kaçabileceği unutulmamalı ve tedbir alınmalıdır. Kulağına ağrıyı azaltmak amaçlı sarımsak sokup çıkaramayan iki hastamızda olduğu gibi internetten elde edilen ve kulaktan dolma geleneksel bilgilerle kulak içine tedavi amacıyla hiçbir yabancı cisim sokulmaması konusunda hastalar bilgilendirilmelidir.

\section{Açıklamalar}

Etik Onam: Çalışma Kütahya Sağılı Bilimleri Üniversitesi Girişimsel Olmayan Klinik Araştırmalar Etik Kurulu tarafından onaylandı (karar no:2020/01-16, tarih:02.01.2020).

\section{Kaynaklar}

1. Da Silva BSR, Souza LO, Camera MG, Tamiso AGB, Castanheira LVR, Foreign Bodies in Otorhinolaryngology: A Study of 128 Cases. Intl Arch Otorhinolaryngol. 2009;13:394-9

2. Fritz S, Kelen GD, Sivertson KT. Foreign bodies of the external auditory canal. Emerg Med Clin North Am. 1987;5:183-92

3. Thompson SK, Wein RO, Dutcher PO. External auditory canal foreign body removal: management practices and outcomes. Laryngoscope. 2003;113:1912-5

4. Olajide TG, Olage FE, Arigbede OO. Management of foreign bodies in the ear: a retrospective review of 123 cases in Nigeria. Ear Nose Throat Journal. 2011;90:E16-9

5. Schulze SL, Kerschner J, Beste D. Pediatric external auditory canal foreign bodies: a review of 698 cases. Otolaryngol Head and neck Surg. 2002;127:73-8

6. İlhan E, Memiş M, Ulucanlı S, Karadeniz D, Yaman H, Güçlü E. Dış 
Kulak Yolu Yabancı Cisimli 117 Hastanın Tanı Ve Tedavisi. KBB-Forum.2014;13:31-4

7. Gül A, Yıldıım H, Yılmaz B, Şengül E, Akdağ M, Özkan H, et al. Dış Kulak Yolunda Yabancı Cisim Tanılı 158 Olgunun Retrospektif Analizi. Kulak Burun Boğaz Uygulamaları. 2014;2:122-5

8. Yeğin Y, Çelik M, Olgun B, Şimşek B, Altıntaş A, Kayhan F. Dış kulak yolu yabancı cisim saptanan olguların değerlendirilmesi. Kocaeli- Medical J. 2017;6;1:45-51

9. Singh GB, Sidhu TS, Sharma A, Dhawan R, Jha SK, Singh N. Management of aural foreign body: an evaluative study in 738 consecutive cases. Am J Otolaryngol. 2007;28:87-90

10. Al-juboori AN. Aural foreign bodies: descriptive study of 224 patients in Al-fallujah general hospital, Iraq. International Journal of Otolaryngology. 2013;2013:401289

11. Bowles PF, Turrell C, Das P. Bialteral aural foreign bodies. Aust Fam Physician. 2016;45(4):200-1.

12. Tonga N L, Modu A, Dajam D. Aural foreign bodies encountered in a tertiary health facility Bingham University Teaching Hospital. Journal of Research \& Method in Education.2019;9(4):59-62

13. Ansley JF, Cunningham MJ. Treatment of aural foreign bodies in children. Pediatrics. 1998;101(4):638-41.

14. Olajuyin O, Olatunya OS. Aural foreign body extraction in children: a double-edged sword. Pan African Medical Journal.2015; 20:186

15. Burke RT, Gatton B, Melville LD. Mastoidits and meningitis complicating an aural foreign body. Pediatr Emerg Care. 2012;28(10):1070-1. 